\title{
Overview of social inequalities in health in the Region of the Americas, using various methodological approaches
}

\author{
George A.O. Alleyne, ${ }^{1}$ Carlos Castillo-Salgado, ${ }^{1}$ Maria Cristina \\ Schneider, ${ }^{1}$ Enrique Loyola, ${ }^{1}$ and Manuel Vidaurre ${ }^{1}$
}

ABSTRACT Over the past decade, according to several important indicators, health conditions have improved in the Region of the Americas. However, inequalities persist among the countries of the Region. This article has two primary objectives: 1) to provide some unbiased evidence on health inequalities among countries of the Region of the Americas and 2) to illustrate the application of some of the more frequently used methods for measuring inequalities, including effect measurements, population attributable risk, the slope index of inequality, the relative index of inequality, and the concentration index. Analyses have shown that there are great health disparities in the Region of the Americas. For example, residents of the poorest countries of the Region live nearly 10 years less, on average, than do residents of the richest countries. If the other countries of the Americas had the same incidence of tuberculosis as does the subregion of North America (Bermuda, Canada, and the United States of America), there would be $76 \%$ fewer cases of this disease in the Region. In the Americas, nearly 35\% of deaths of infants under 1 year old are concentrated in the $20 \%$ of live births that occur in the group with the lowest income. As for maternal mortality in the Americas, fewer than $2 \%$ of maternal deaths occur in association with the $20 \%$ of live births in the group with the highest income. The analyses of health inequalities based on the use of various methods highlight the existence of important disparities among subregions and countries of the Americas that are not readily seen when using only the more-traditional methods for analyzing mortality and morbidity. There is also a need to incorporate the concepts of distribution and socioeconomic dimensions of health when interpreting a given situation. Using this approach will allow decisionmakers to target areas and populations that are in less-favorable conditions. A considerable body of aggregate data at the Regional and country levels from routine information systems is already availableóespecially on morbidity, mortality, and other health-related factorsóthat can be used on a regular basis to analyze health inequalities. These kinds of analyses may be regarded as a first step toward the identification of health inequities.

Key words Equity, health status, health status indicators, socioeconomic factors, Americas.

1 Pan American Health Organization, Washington, D.C., United States of America. Send correspondence to: Carlos Castillo-Salgado, Special Program for Health Analysis, Pan American Health Organization, 525 23rd Street, N.W., Washington, D.C. 20037, United States of America; e-mail: sha@ paho.org
Over the past decade, health conditions have been steadily improving in the Region of the Americas, according to several indicators. This progress is the result of various social, environmental, cultural, and technological fac- tors as well as the expanded coverage of health care services and public health programs. Nevertheless, these improvements have not shown the same intensity or momentum in every country or in every population group 
within each country. Several publications from the Pan American Health Organization (PAHO) have documented the inequalities that still exist among the countries and within specific countries (1-4).

Narrowing inequalities and making the goal of ihealth for allî a reality in the medium term represents a challenge for governments, $\mathrm{PAHO}$, the World Health Organization (WHO), and other agencies that are active in the health sector. The search for equity in health is a vital concern for the Region of the Americas, particularly in Latin America and the Caribbean, as has been set forward in various PAHO publications $(2,5)$. This is especially true given that the countries of the Region of the Americas display the most inequitable income distributions in the world (6). Gathering objective evidence about disparities in health conditions is the first step toward identifying health inequities.

Although they are related, the concepts of inequality and of inequity are distinct. Inequalities are simply differences. Inequities, on the other hand, are unfair and avoidable inequalities, and they are crucial in defining public health policies. The analysis of inequities must seek to determine their causes and how likely they are to be unfair and avoidable.

This article will focus on inequalities rather than inequities. The piece has two primary objectives: 1 ) to provide some unbiased evidence on health inequalities among countries of the Region and b) to illustrate the use of some of the more frequently used methods for measuring inequalities, using data from routine information systems. The use of a variety of methods to analyze health inequalities makes it possible to define the existence of disparities among subregions and countries that are not readily observed when using only the moretraditional methods for analyzing mortality and morbidity. In addition, an approach incorporating the concepts of distribution and socioeconomic dimensions of health shows decisionmakers the need to target areas and populations that are in less-favorable conditions.

For PAHO, the search for equity in health is more than just a theoretical issue; it also offers a solid framework for technical cooperation with the PAHO Member Countries. Measuring and monitoring inequalities in health is of paramount importance in decisionmaking for formulating health policies and for orienting health services and programs in national and local governments. PAHOís technical cooperation with its Member Countries should focus on identifying inequalities in health and formulating effective strategies for reducing and ultimately eliminating those inequalities.

\section{GENERAL SITUATION AND TRENDS IN THE AMERICAS}

\section{Socioeconomic context}

The Region of the Americas has the highest level of inequality in terms of per capita income distribution of any region in the world. In Latin America in 1990, the wealthiest $20 \%$ of the population earned $52.4 \%$ of the areaís income, while the poorest $20 \%$ earned only $4.5 \%$, for a ratio of $11.6: 1$ (6). This contrasts, for example, with the highly industrialized countries of the Organization for Economic Cooperation and Development (OECD), where the income percentages were $39.8 \%$ for the wealthiest quintile and $6.3 \%$ for the poorest quintile, for a ratio of 6.3:1. Latin Americaís income gap has worsened over the course of the last several decades. The income ratio between the wealthiest $1 \%$ and the poorest $1 \%$ was $363: 1$ in 1970 . In the 1980s, the ratio dropped to $237: 1$ in the wake of an economic crisis. The subsequent economic recovery, however, was followed by a disproportionate concentration of income in the wealthiest sector of the population, with the income ratio reaching 417:1 in 1995.

Among the countries of the Region, the 1996 per capita gross national product (GNP) adjusted for purchasing power parity showed broad varia- tions, ranging from US\$ 1130 in Haiti to US\$ 28020 in the United States of America (7).

\section{Demographic setting}

The Region of the Americas, and especially the subregions of Latin America and the Caribbean, continues to experience demographic and epidemiological transitions. All the countries are witnessing the aging of their populations, lower fertility rates, and rapid urbanization.

Between the first half of the 1980s and the second half of the 1990s, life expectancy at birth rose from 69.2 to 72.4 years for the Region as a whole (8). For the 1995-2000 period, the figure has been estimated at 76.9 years for the subregion of North America (Bermuda, Canada, and the United States of America), but at only 69.8 years for Latin America and the Caribbean. In all the subregions of the Western Hemisphere, women enjoy higher life expectancies, on average, than do men.

As a consequence of various strategies that have been pursued, fertility in the Americas dropped between 1980 and 1995 (8). Over the period, the total fertility rate dropped from 3 to 2.4 children per woman. Between 1990 and 1995, fertility rates in the Region ranged from 5 or more children to fewer than 2. The Regionís population growth has slowed, declining from an average annual increase of $1.6 \%$ in 1980 to $1.3 \%$ in 1995. Even so, some countries of the Caribbean, Central America, and the Southern Cone still have population growth rates above $2.5 \%$.

The steady flow from rural to peripheral urban areas is changing the demographic profile of the Region of the Americas, and this is affecting the populationís health and health care services. Between 1980 and 1995, urbanization was spurred by natural growth and also by rural-to-urban migration, with families moving to cities in search of work and better living conditions. In 1980, the rural population represented $31 \%$ of the total pop- 
ulation of the Americas, ranging from a low of $20 \%$ in the Southern Cone to a high of $58 \%$ in Central America (8). Estimates for the year 2000 indicate that rural residents will account for $24 \%$ of the total, ranging from $15 \%$ in the Southern Cone to $52 \%$ in Central America.

\section{Environmental context}

In 1997 an estimated $80 \%$ of the Regionís population had household water connections or easy access to safe water, ranging from $91 \%$ in North America to $67 \%$ in Central America (8). Seventy percent of the population had access to disinfected water, an enormous advance over the $20 \%$ of 10 years before. Despite the progress made in recent decades, rural populations had disparate levels of coverage of household water connections or easy access to safe water in 1995, ranging from over $80 \%$ to below $20 \%$. Sanitary sewerage systems continued to have very limited coverage, although the percentage of the population without access to those systems was reduced from $35 \%$ in 1980 to $24 \%$ in 1997. Coverage of sanitary sewage systems at the subregional level showed marked differences, with a level of $67 \%$ in the Andean area and Brazil versus $94 \%$ in the non-Spanish-speaking Caribbean. In addition, although progress had been made, only $10 \%$ of the wastewater collected in the entire Region received some kind of treatment prior to final disposal.

\section{Mortality and morbidity}

Infant mortality rates (IMRs) are estimated to have decreased from 36.9 to 24.8 per 1000 live births in the Region overall between 1980ñ1985 and 1995ñ 2000; the decline in Latin America and the Caribbean was from 55.3 to 35.5 per 1000 (8). This indicator shows a significant degree of inequality among countries. For instance, when the countries were grouped into five categories according to 1996 GNP per capita, the IMR for the highest-income
FIGURE 1. Infant mortality inequalities by gross national product per capita groups in the Americas, 1996

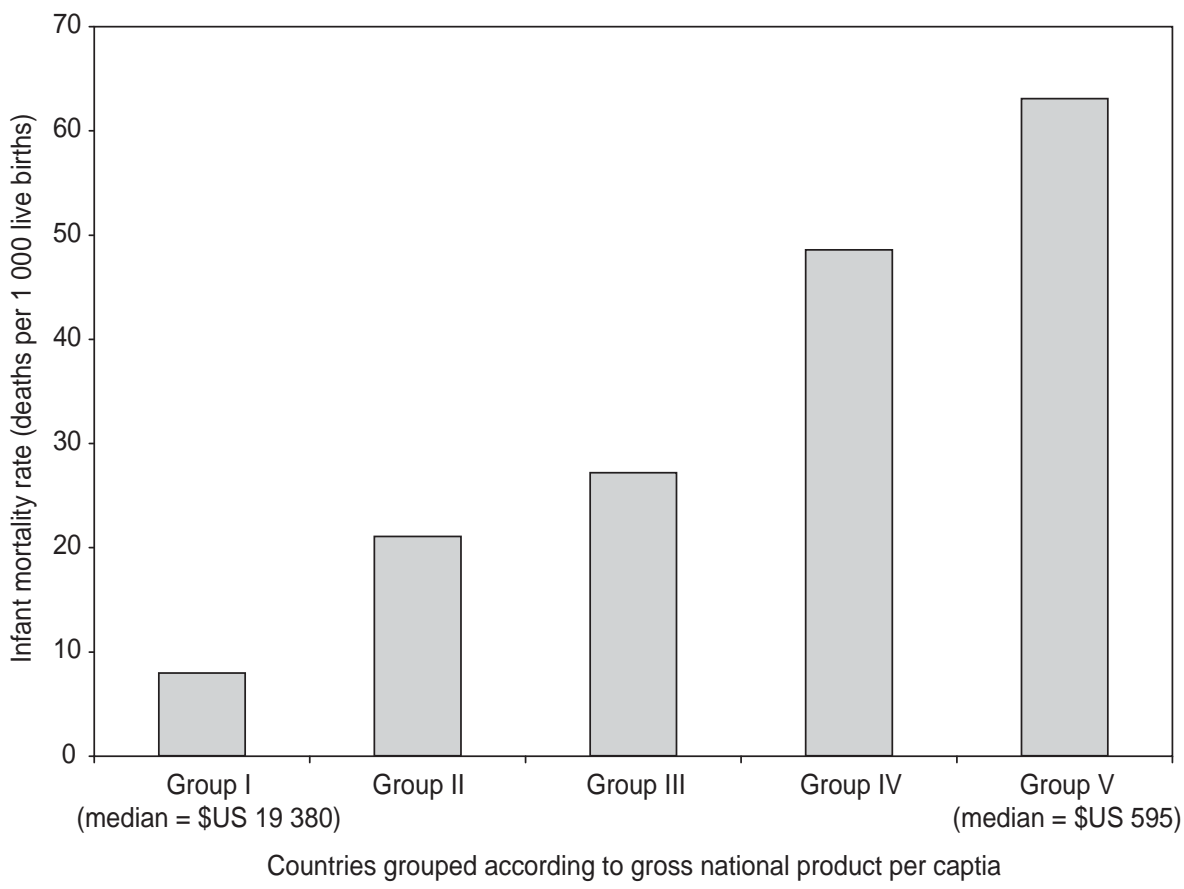

group was one-eighth the rate for the lowest-income group (Figure 1).

Despite natural population growth and an increase in the total number of deaths, between 1980 and 1994 the Region had a drop of more than $20 \%$ in the number of potential years of life lost, that is, in the number of premature deaths (ones occurring before age 75) (4). Although part of this change can be attributed to the aging of the population, the main cause was the reduction in child mortality, especially from communicable diseases (9). However, since this reduction occurred to differing degrees in the various countries, inequalities among the countries persisted, and increased in many cases (4). Currently, noncommunicable diseases account for roughly two-thirds of all deaths in Latin America and the Caribbean.

The situation with regard to low weight-for-age and low weight-forheight, especially among children under 5 years of age, has generally improved in the Region of the Americas. Nevertheless, the prevalence of nutri- tion-related low height-for-age, which reflects periods of inadequate nutrition, continues to be very high, at over $10 \%$ for the Region and affecting nearly $50 \%$ of preschool and school-

Obesity and overweight have increased rapidly in the Region, especially among lower socioeconomic strata, in urban areas, and among women (4). Obesity cannot be viewed any more as a nutritional problem of iexcess,î because it usually coexists with specific deficiencies of micronutrients such as iron, folic acid, and zinc.

The above information highlights the presence of important disparities in both the health status and the living conditions of segments of the population in the Americas. To further address the nature and distribution of those disparities, there is a need for other analytical methods that consider all the groups in the population as well as socioeconomic inequalities in health. The following section will include some of aged children in some countries (4). 
those methods, with specific examples of their application.

\section{MEASURING HEALTH INEQUALITIES IN THE AMERICAS}

The indicators that were used in this paper to document inequalities are based on data on morbidity, mortality, and factors associated with health status drawn from PAHO's Regional Core Health Data System and PAHO's Technical Information System (7). The Regional Core Health Data System is a Web-based system involving a set of 117 core health indicators that are required in most health situation analyses. The indicators include ones for demographic and socioeconomic characteristics as well as morbidity, mortality, risk factors, resources, and access to and coverage of health services. The Technical Information System is a mortality and population information system that stores, adjusts, and produces tabular data on specific causes of death by age and sex. These two systems include data from all the countries of the Americas, for a period of at least 10 years.

Several important methodological studies have been conducted on measuring health inequalities, such as those of Mackenbach and Kunst (10, 11) and of Wagstaff, Paci, and Van Doorslaer (12). Good indicators of inequality should: 1) reflect the socioeconomic dimension of health inequalities, i.e., the fact that the inequalities are systematically related to socioeconomic status; 2) reflect the experience of the population as a whole, i.e., use information available on all population groups; and 3) be sensitive to changes in the distribution and size of the population across socioeconomic groups $(11,12)$.

The methodology that we adopted to analyze health inequalities is based on a comparison of indicators and measurements that include health as an important component; those indicators and measurements are stratified by the countriesí socioeconomic status. We express the comparisons of the health situation across socioeconomic groups both in absolute terms (i.e., without reference to a given standard) and in relative terms (i.e., in relation to a benchmark).

In studying health inequalities, one can choose to use either measurements of effect or measurements of impact, depending on the type of question being addressed. In contrast to measurements of effect, measurements of impact take into account the actual socioeconomic situation and measure changes in health conditions that are to be expected as a result of potential interventions. (The relationship between effect and impact can be likened to the one existing between ìrelative riskî and ìattributable riskî in epidemiology.) For this reason, measures of impact are particularly relevant for decision-making and for public health policies aimed at achieving equity.

In the following sections we will present examples of both effect and impact measurements for assessing inequalities, and we will also highlight the interpretation and significance of the results.

\section{Effect of health inequalities}

Effect indicators are often used to document the presence of inequalities in health. The Black Report (13), a pioneering study conducted in the 1980s, used effect indicators to describe the presence of inequalities in mortality by social class in England and Wales.

Effect indicators can express both relative and absolute inequalities. This can be seen with the example of maternal mortality in the Southern Cone subregion for the period between 1992 and $1997(7,8)$. The ratio of the maternal mortality rate (MMR) in the country with the lowest 1996 GNP per capita to that of the country with the highest 1996 GNP per capita was 4.9:1 (123 per 100000 live births versus 25 per 100000 live births), and the difference in rates was 98 per 100000 (i.e., $123-25=98$ ). These figures indicate that pregnant women in the most-disadvantaged Southern Cone country faced nearly five times as much risk of dying during pregnancy, delivery, or puerperium as compared to women in the country with the best socioeconomic status; the absolute value of this health inequality represents an excess of 98 maternal deaths per 100000 live births in the less-favorable situation.

We conducted a similar analysis to measure the differences in life expectancy at birth in 1998 in the Region of the Americas. We ranked countries with a population of more than 500000 according to their 1996 GNP per capita, and then we calculated the median life expectancy (MLE) for the top and bottom quintile groups of countries. The MLE at birth was 76 years in the upper quintile versus 66.5 years in the lower quintile. In other words, residents of the poorest countries were thus expected to live nearly 10 years less on average than those in the richest countries. This difference may be even greater between different socioeconomic groups within specific countries.

Some measures of effect, including those presented above, may be criticized on the grounds that they overlook inequalities among groups or categories (in this case, countries) not included in the comparison, that is, groups between the extreme values, or in the middle of the distribution. This shortcoming can be overcome by fitting linear regression models that use all the information contained in the data distribution and not just the data that are contained in the extreme groups involved in the comparison. In contrast to the analysis of categories presented above, a simple linear regression model assumes a continuous data distribution, where the slope (b) is a measure of absolute effect and represents the average change in a given health variable for each unit of change in some socioeconomic variable (10ñ 12). We applied this approach to an analysis of infant mortality in Central American countries in 1997, using the percentage of the population with access to drinking water as the socioeconomic variable. Figure 2 shows the correlation between access to safe water and infant mortality. The slope of the regression line $(b=-0.53)$ indicates that, on average, for each $10 \%$ in- 
FIGURE 2. Infant mortality and population access to safe drinking water in Central America, 1997

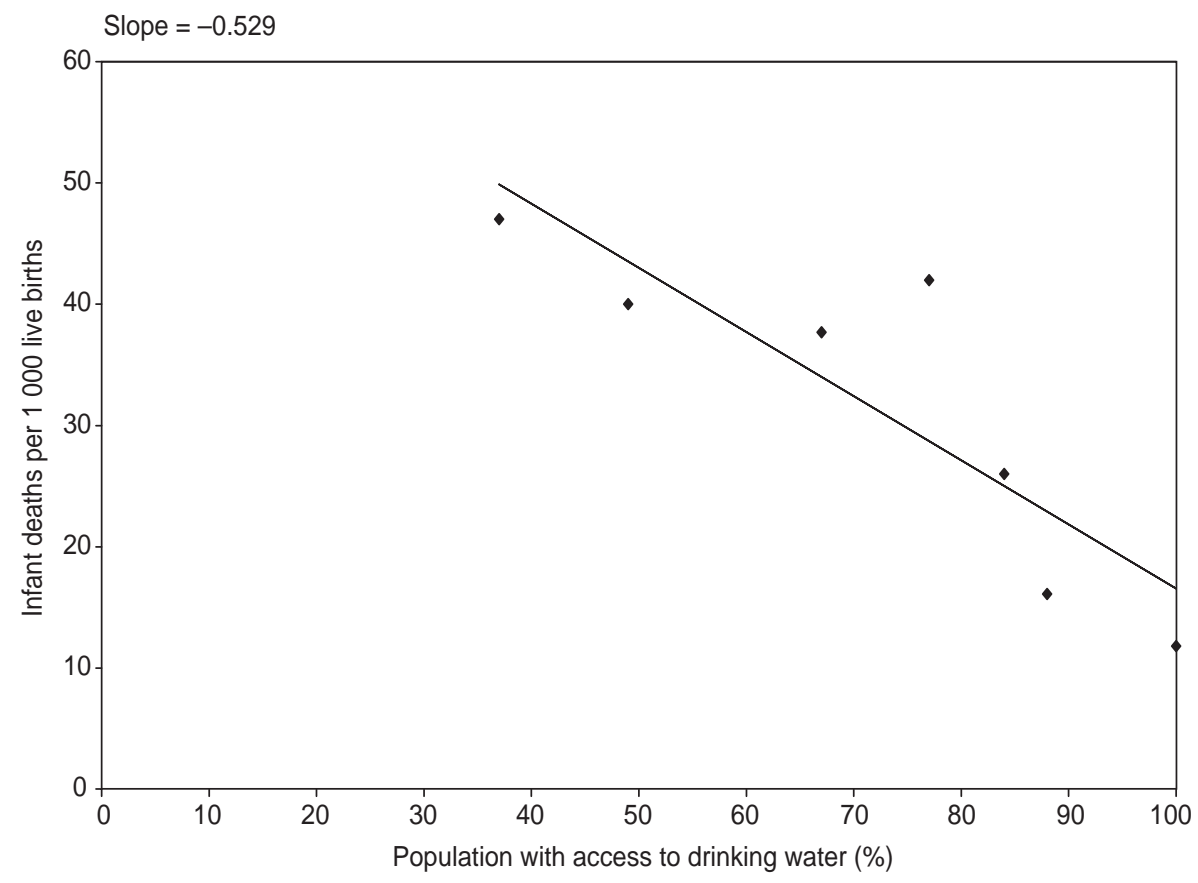

crease in access to drinking water, infant mortality drops by nearly 5 deaths per 1000 live births.

\section{Impact of health inequalities}

The indicators of impact express the ìadjustedî effect of socioeconomic inequalities on the health of the population as a whole, taking into account the size of the socioeconomic groups (10ñ12). Since the size and distribution of the most disadvantaged socioeconomic groups are influenced by sectors outside the health sphere, such as the economic and education sectors, measures of impact are felt to reflect the intersectorally modifiable dimension of health inequalities. To assess the impact of socioeconomic inequalities, there are different approaches, based on analyses of groups and on regression models. We will refer to both of them in the following paragraphs.

One of the most widely used indicators of overall impact in the health sector is the population attributable risk
(PAR), which can be both relative and absolute $(10,11)$. The PAR can be used to estimate the percent reduction in overall morbidity or mortality that would occur if all the countries had the same rate as the group of countries with the highest socioeconomic level (the reference group). The advantage of this indicator is that it is easy to calculate and interpret. The further PAR lies from zero, the greater the inequality and the greater the potential for reduction. We used the PAR (\%) to measure relative inequalities associated with mortality from acute respiratory infections (ARIs) among children under 5 years old in the Americas. The North America subregion, where ARI mortality was 0.16 per 1000 live births in 1993, was selected as the reference category (i.e., the group in the best situation). For the Region of the Americas as a whole, the ARI mortality rate was 2.18 per 1000 live births. The PAR is therefore $92.7 \%$, which means that if all the countries had the same ARI mortality rate for children under 5 years old that the North America subregion does, there would be $93 \%$ fewer deaths among this age group from this cause in the Region of the Americas.

Using another approach for calculating the PAR (\%) based on different groups instead of the whole Region, we used weighted rate ratios to study the inequalities in the incidence of tuberculosis in the Americas. Again, the reference category was North America, with 8 cases per 100000 population and $38 \%$ of the total population of the Americas. The following incidence rates were reported $(7,8)$ for other subregions of the Americas: 74 per 100000 in the Andean area $(13 \%$ of the total population of the Americas), 35 per 100000 in the Southern Cone $(7 \%$ of the population), 55 per 100000 in Brazil (21\% of the population), 39 per 100000 in Central America (4\% of the population), 18 per 100000 in Mexico (12\% of the population), 48 per 100000 in the Latin-speaking Caribbean (4\% of the population), and 11 per 100000 in the non-Latin-speaking Caribbean ( $1 \%$ of the population). We calculated the PAR as being $76 \%$. This indicates that if the other subregions of the Americas had the same incidence of tuberculosis as North America, there would be $76 \%$ fewer cases of this disease in the Region.

One of the limitations of the PAR is that it does not take into account the socioeconomic status differences of groups or countries. To solve this limitation, regression-based indicators such as the slope index of inequality (SII) and the relative index of inequality (RII) are used (10ñ12). For SII and RII, groups are ranked according to socioeconomic status (from lowest to highest) and their relative position in the cumulative population distribution is regressed on the health variable. The slope of the regression line (b) represents the SII and expresses the magnitude of the change in the health variable per unit of change in relative position in the socioeconomic hierarchy. The RII reflects how many times as great the morbidity/mortality rate of the bottom (i.e., lowest) socioeconomic group is in comparison to the top group. The higher the value of the SII and the RII indicators, the greater the inequality between the groups. 
FIGURE 3. Mortality among children under 5 years of age and socioeconomic levels in selected countries of the Caribbean, 1997

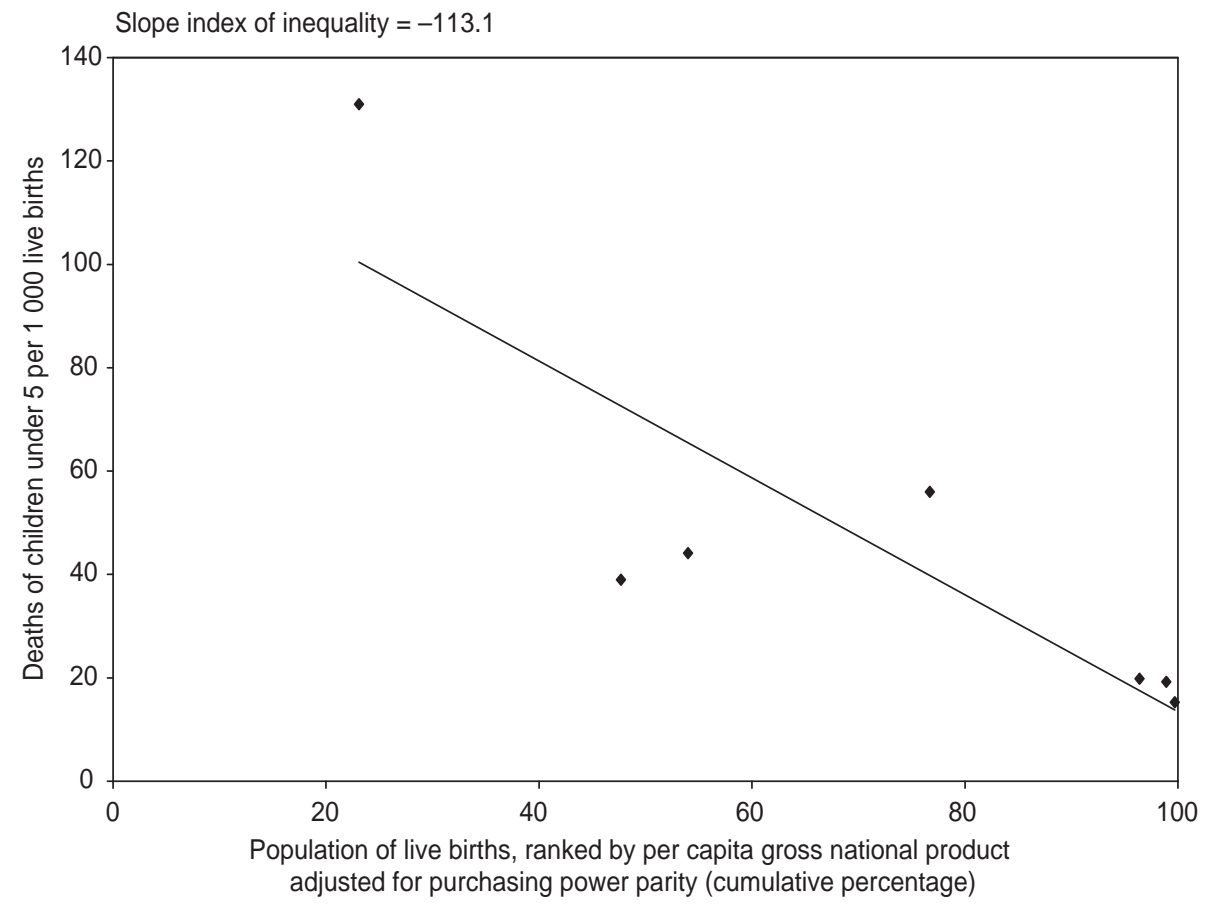

Both indicators consider the population size, and they are sensitive to the average health status. Also, it is necessary to verify both the linearity assumptions for the regressions and the model fit.

We calculated the SII and RII for mortality for children under 5 years old in Caribbean countries with more than 150000 inhabitants, based on the cumulative population of live births ranked by 1997 GNP per capita (Figure $3)$. The country with the best socioeconomic situation had a mortality rate of 15.3 per 1000 live births for this age group. The country with the worst socioeconomic situation had a calculated rate of 131 per 1000 live births. The regression analysis (using weighted least squares methods) yielded an SII (b) of ñ113.1, which means that the most-disadvantaged country experienced 113.1 more deaths of children under 5 years per 1000 live births than did the country with the best conditions.

We calculated the RII as the ratio between the slope of the regression (113.1) and the value for the highest socioeconomic status (15.3). This ratio takes into account the whole population and indicates how many times as great the rate of the lowest socioeconomic group was in comparison to the rate for the highest group. The resulting RII was 7.4, indicating that the death rate in children under age 5 in the lowest-income Caribbean country was some seven times as high as the rate in the highest-income country in the area.

\section{Measuring inequality with the Gini coefficient and the concentration index}

The indicators presented above provide information on the magnitude of effect and impact of socioeconomic inequalities in health. However, they offer little information about the distribution of health status according to the distribution of the population or to the socioeconomic status of populations. Alternative indicators that consider those two aspects, respectively, are the Gini coefficient and the concentration index.
The Gini coefficient is a measure of inequality that has been widely used in economics and that is now being applied in the health field (10ñ12). It is based on the Lorenz curve, a graphic representation of cumulative frequencies that compares the actual distribution of a variable in the population with a uniform distribution. The uniform distribution is represented by a diagonal line with a slope of 1 that goes through the origin of a system of Cartesian axes. The further the Lorenz curve is from this line, the greater is the inequality. Thus, the Lorenz curve provides a visual representation of inequalities. The Gini coefficient is twice the area of the graph between the Lorenz curve and the diagonal of the uniform distribution. The values of the Gini coefficient range from 0 to 1 , representing, respectively, perfect equality and perfect inequality of the variable distribution.

If income distribution were absolutely equal among the population, this would yield a null Gini coefficient. However, in the Region of the Americas in 1995 the Gini coefficient was calculated at 0.33 (7). The associated Lorenz curve shows that the wealthiest $30 \%$ of the population earned roughly $60 \%$ of the Regionís income (Figure 4). The same approach could be used to assess the distribution of a health variable, such as infant mortality, rather than income. In that case, the cumulative proportion of infant deaths by country would be plotted against the cumulative proportion of live births; both the Lorenz curve and its interpretation would be similar to the income example.

It is widely recognized that differences in health are related to differences in socioeconomic status. Attempts to use the Lorenz curve and Gini coefficient to assess socioeconomic inequalities in health are not sufficient because only one dimension (either an economic one or a healthrelated one) may be incorporated in the analysis at a time. To overcome the limitation of analyzing a health variable while also considering socioeconomic inequalities, the concentration index is used. By organizing the pop- 
FIGURE 4. Lorenz curve showing income distribution in the Americas by country, 1996

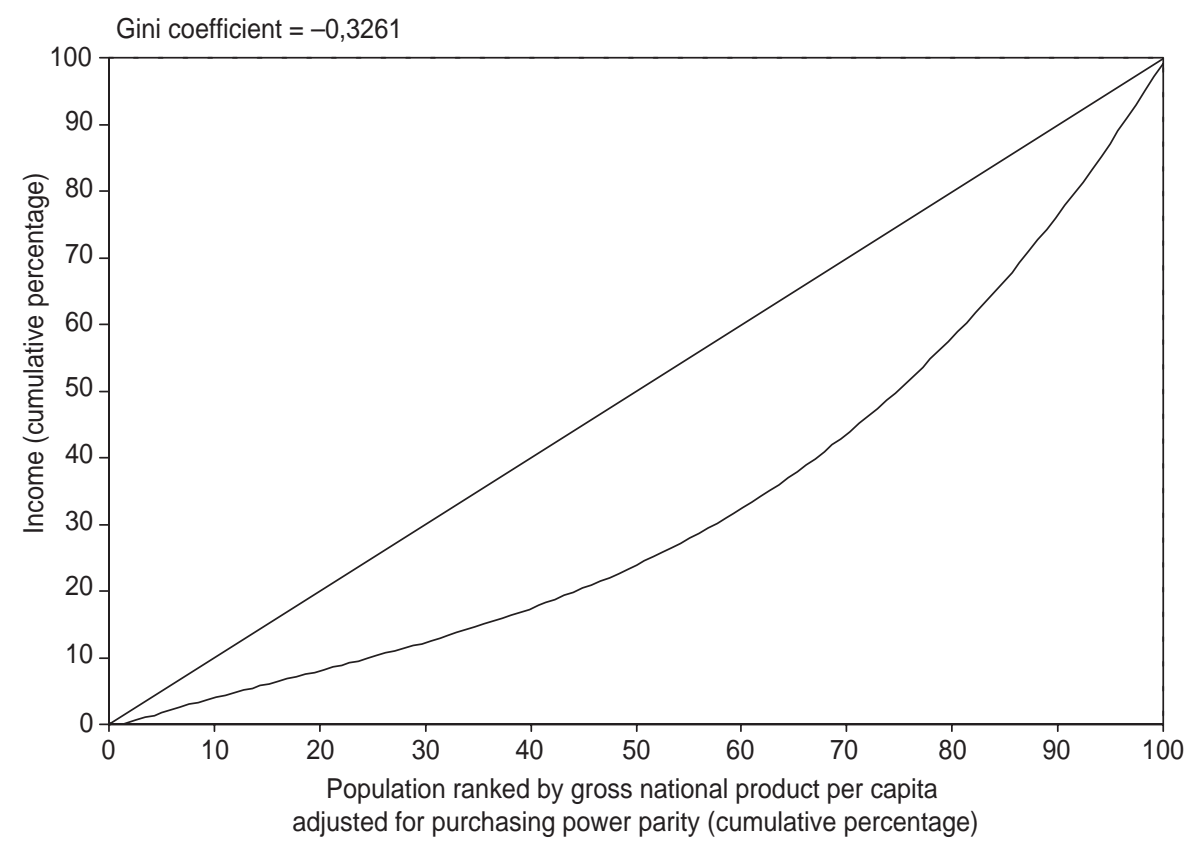

FIGURE 5. Concentration curve showing distribution of infant mortality and gross national product (GNP) in countries of the Americas, 1997

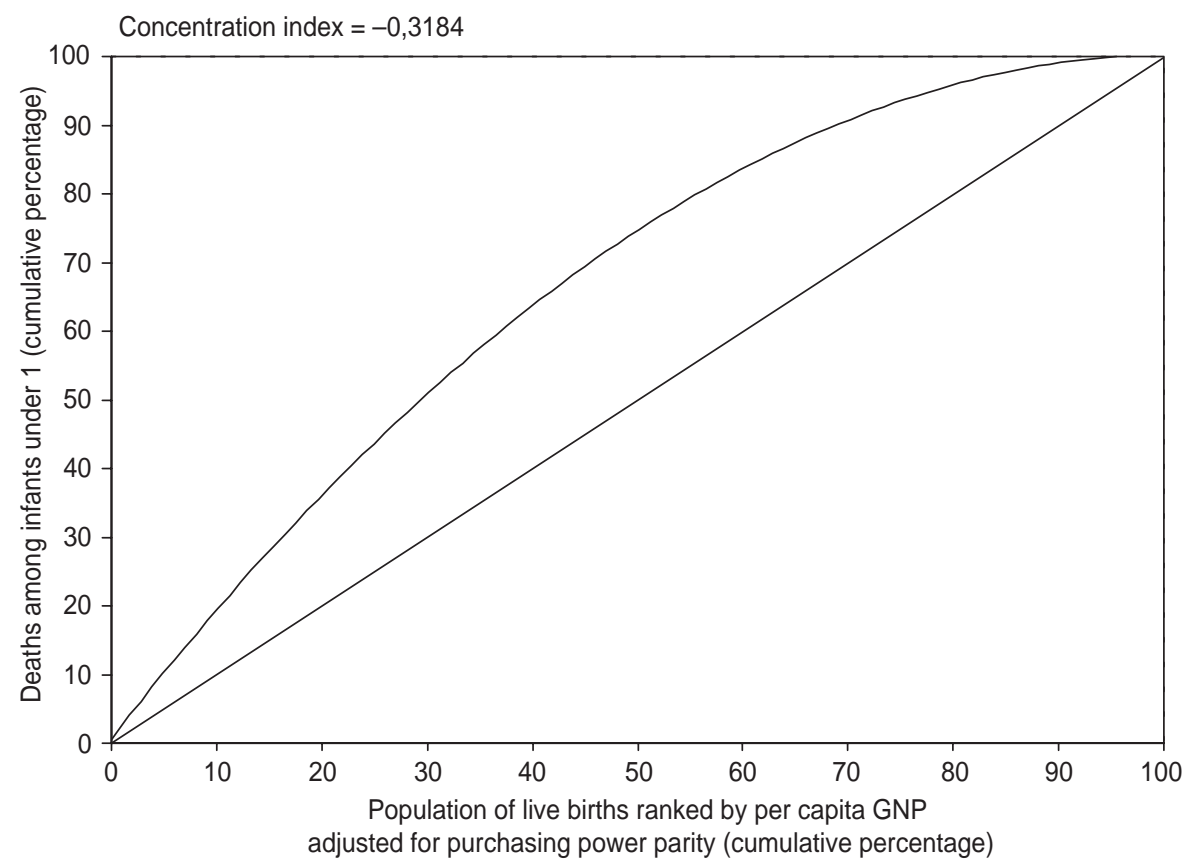

ulation hierarchically according to a particular socioeconomic variable (e.g., GNP per capita), rather than by the cumulative population proportion, it is bution of the health indicator in relation to a socioeconomic variable, thus yielding a measure of socioeconomic inequality (10-12). In contrast to the Gini coefficient, the concentration index varies from -1 to +1 , with a value further away from zero indicating greater inequality. When the index is negative, the Lorenz curve appears above the diagonal, and the health events are concentrated among the group that is the least privileged socioeconomically.

We calculated the concentration index for infant mortality in 1997 in the Region of the Americas as being ñ0.32 (Figure 5). We also calculated the index for maternal mortality over the 1992-1997 period and found it to be -0.48 (Figure 6). With these negative index values, the respective concentration curves are located above the diagonal line, indicating a concentration of mortality in the moredisadvantaged socioeconomic groups. The concentration curve for infant mortality indicates that nearly $35 \%$ of deaths of infants under 1 year old were concentrated in the $20 \%$ of live births that occurred in the group with the lowest income (Figure 5). As for maternal mortality (Figure 6), fewer than $2 \%$ of the maternal deaths occurred in association with the $20 \%$ of live births in the group with the highest income.

Cardiovascular diseases are one of the leading causes of mortality among the population aged 45 and older, accounting for approximately $30 \%$ of all deaths in the Region of the Americas $(7,9)$. We analyzed the distribution of these diseases by country groupings, organized according to socioeconomic status. Figure 7 shows the concentration curve for mortality from this cause over the five-year period of 1990ñ1995; the respective concentration index is $\tilde{n} 0.03$. The curve indicates a low degree of inequality in this variable for the period mentioned. This same pattern was observed when different age groups and periods were analyzed. Various explanations have been offered for this situation, including competing risks for different causes of death, the effect of rapid 
FIGURE 6. Concentration curve showing distribution of maternal mortality and gross national product (GNP) in countries of the Americas, 1992-1997

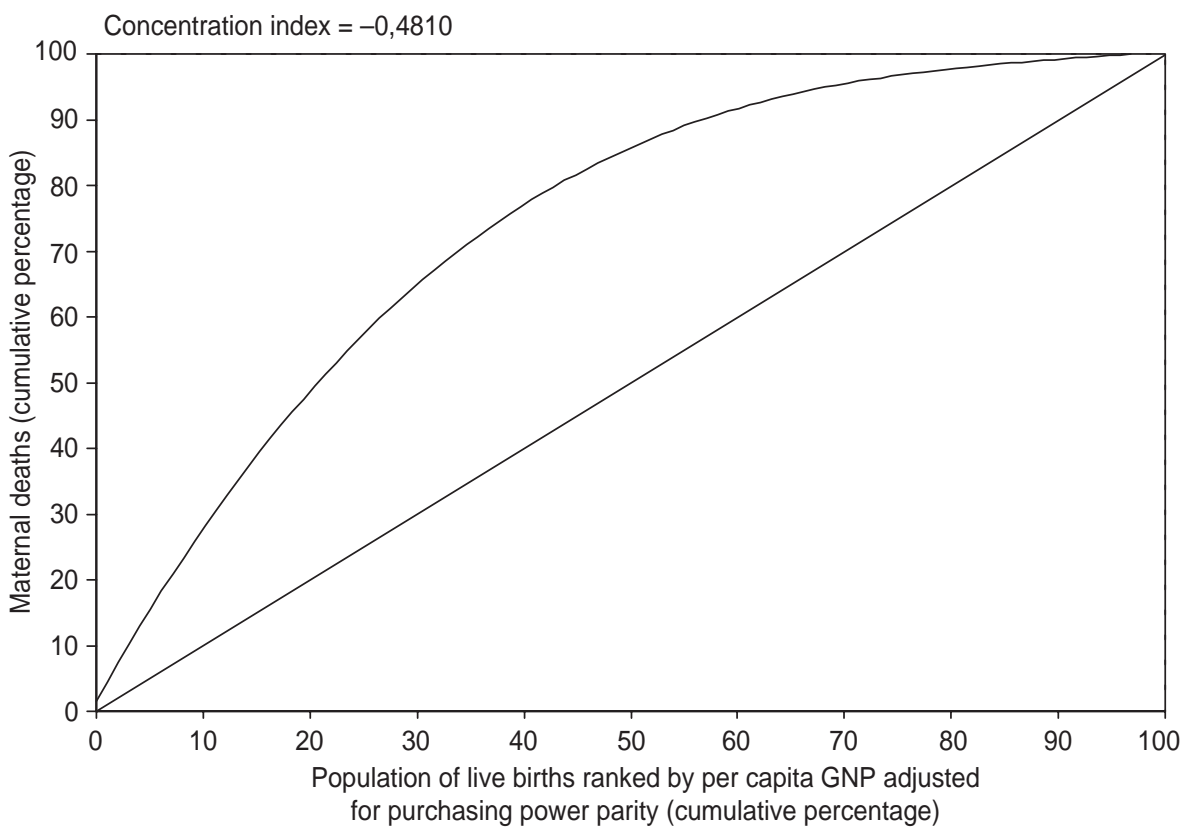

FIGURE 7. Concentration curve showing distribution of cardiovascular mortality and gross national product (GNP) in countries of the Americas, 1990-1995

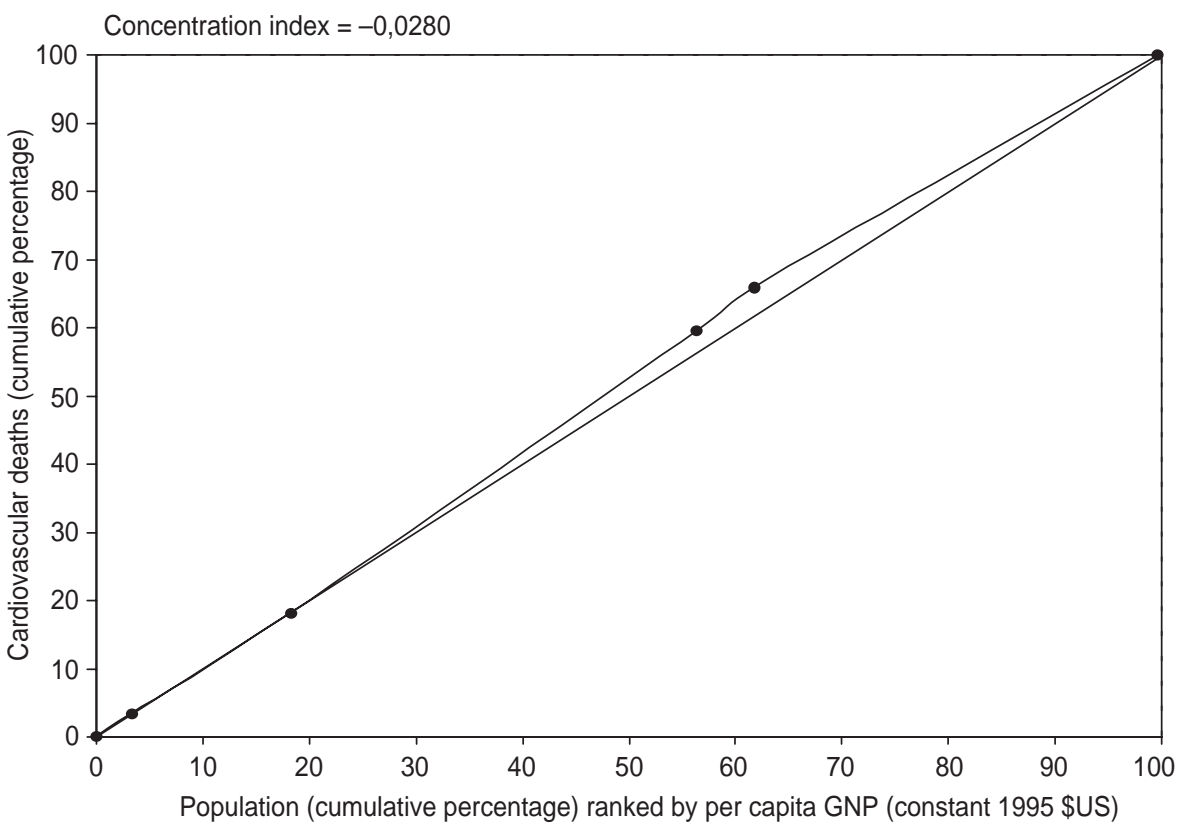

lifestyle changes in the poorest countries, the impact of longer life expectancies (or survival rates) and the subsequent increase in the risk of
This findingówhich has been replicated in other studies in China, India, Mexico, and the United States (14)ó merits further investigation in order to identify the relevant determinants.

Figure 8 depicts the distribution of physicians in the Region of the Americas around 1997. The concentration index is +0.18 , with the curve showing a concentration of physicians among the wealthiest socioeconomic groups. The $20 \%$ of the population earning the highest incomes accounted for $70 \%$ of the physicians in the Region.

\section{INFORMATION ON HEALTH INEQUALITY AS AN INPUT FOR POLICY-SETTING}

Health gains affect economic growth and development. In the Region of the Americas, achieving greater equity in health is an objective shared by the governments and by PAHO, and it is a crucial stepping stone towards attaining sustainable human development, for which health is one of the essential elements. Today more than ever, efforts need to focus on identifying, measuring, and reducing inequalities in living conditions and in access to and use of health services (15).

Using some very well-known inequality measures and several selected health indicators, this article shows examples of great disparities in the Region of the Americas. This descriptiveanalytical approach is a first step toward identifying health inequities. A considerable body of aggregate data from vital statistics and routine information systems is already available, especially on morbidity, mortality, and other health-related factors that have been assigned priority by the governments in the Region of the Americas. This information can be used on a regular basis at the various geopolitical levels (Regional, national, and local) to analyze health inequalities.

PAHO recognizes that information indicating an inequitable situation in a specific aspect of health should translate into action, such as policy decisions aimed at diminishing inequity and ultimately eliminating it. The ob- 
FIGURE 8. Concentration curve showing distribution of physicians and gross national product (GNP) in countries of the Americas, 1997

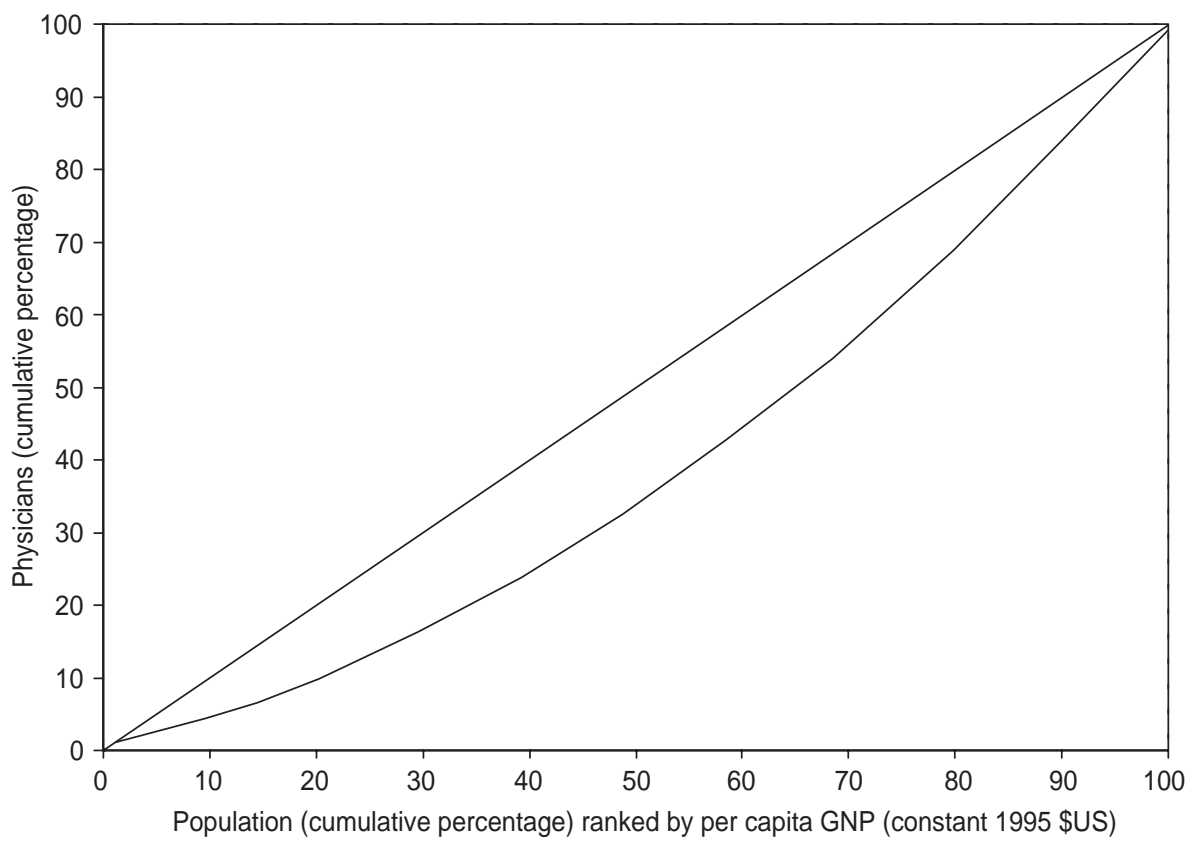

jective documentation of health inequalities is a vital prerequisite for defining such actions. National capacity needs to be built up in the Region in order to analyze data and information on health inequalities. Once inequality-specific interventions have been designed and implemented, the same methods of measurement and analysis will serve to monitor and assess their impact on health.

There is a close relationship between interventions and the techniques used to measure inequalities. In Brazil, for example, health analyses at the regional and state levels have made it possible to identify notable inequalities between the South and the North and the Northeast of the country (16). Three main macrodeterminantsó poverty, urbanization, and aspects of health service organizationóseem to explain these large differences. These factors may act together to promote poor living conditions and to limit access to social and health services. The identification of these factors will enable health managers and decisionmakers to define appropriate health interventions.

The choice of a methodology for assessing health inequalities must be subordinated to the existence of a repertoire of feasible and foreseeable actions. If those actions seem to indicate the need for the design of population-wide intersectoral policies, then disparities should be documented by means of impact measures. However, if the likely actions are selective and intrasectoral, disparities should be expressed by means of effect measures.

For $\mathrm{PAHO}$, analyzing health inequities and setting equitable health policies holds special importance. These activities are part of PAHOís mandate, and they provide input for setting priorities for technical cooperation. The search for equity is not only a theoretical issue, but a concrete basis for technical cooperation. Health equity is also imperative in achieving the economic development of the Region.

\section{REFERENCES}

1. Pan American Health Organization. Health conditions in the Americas, 1994 edition. Volume I. Washington, D.C.: PAHO: 1994. (Scientific Publication No. 549).

2. Pan American Health Organization. Annual report of the Director, 1995. The search for equity. Washington, D.C.: PAHO; 1996. (Official Document No. 277).

3. Pan American Health Organization. Annual report of the Director, 1996. Healthy people, healthy spaces. Washington, D.C.: PAHO; 1997. (Official Document No. 283).

4. Pan American Health Organization. Health in the Americas, 1998 edition. Volume I. Washington, D.C.: PAHO; 1998. (Scientific Publication No. 569).

5. Pan American Health Organization. Annual report of the Director, 1998. Information for health. Washington, D.C.: PAHO; 1999. (Official Document No. 293).

6. Deininger K, Squire L. A new data set measuring income inequality. World Bank Econ Rev 1996;10:565-591.

7. Pan American Health Organization, Special Program for Health Analysis. Regional Core Health Data Initiative; Technical Health Information System. Washington, D.C.: PAHO; 2001.

8. Pan American Health Organization, Special Program for Health Analysis. Health situation in the Americas. Basic indicators 1999. Washington, D.C.: PAHO; 1999.

9. Pan American Health Organization. Health statistics from the Americas, 1998. Washington, D.C.: PAHO; 1999. (Scientific Publication No. 567).
10. Mackenbach JP, Kunst A. Measuring the magnitude of socio-economic inequalities in health: an overview of available measures illustrated with examples from Europe. Soc Sci Med 1997;44:757-771.

11. Kunst AE, Mackenbach JP. Measuring socioeconomic inequalities in health. Geneva: World Health Organization; 1994. (EUR/ICP/RPD 416).

12. Wagstaff A, Paci, P, Van Doorslaer E. On the measurement of inequalities in health. Soc Sci Med 1991;33:545-557.

13. Townsend $P$, Davidson N. Inequalities in health. The Black Report. London: Penguin Books; 1988.

14. Murray CJL, Lopez AD. Estimating causes of death: new methods and global and regional applications. In: Murray CJL, Lopez AD, eds. 
The global burden of disease. Geneva: World Health Organization; 1996. Pp. 118-200.

15. Alleyne GAO. La salud en el marco de reducción de la pobreza. 5ta. Reunión del Foro Permanente para la Aplicación de la Estrategia de Cooperación al Desarrollo. Lima, Perú: Orga- nización Panamericana de la Salud; 1998. (OPS/PER/99.03).

16. Duarte EC, Schneider MC, Paes-Sousa R, Ramalho WM, Vasconcelos LM, Barbosa J, et al. Epidemiologia das desigualdades em sa de no Brasil. Un estudio exploratório. Brasìlia: Organização Pan-americana da Saúde; 2002.

Manuscript received 7 February 2002. Accepted for publication on 22 February 2002.

ABSTRACT Según varios indicadores importantes, las condiciones de salud han mejorado en la Región de las Américas a lo largo de la pasada década. Sin embargo, sigue habiendo desigualdades entre los países de la Región. Este artículo tiene dos objectivos principales: 1) aportar algunos datos objetivos sobre las desigualdades de salud entre los paÌses de la Región de las Américas, y 2) ilustrar la aplicación de algunos de los métodos utilizados con más frecuencia para medir las desigualdades, como las mediciones de efecto, el riesgo atribuible poblacional, el Ìndice de desigualdad de la pendiente, el İndice relativo de desigualdad y el índice de concentración. Los análisis muestran que hay grandes disparidades de salud en la Región de las Américas. Por ejemplo, los residentes en los países más pobres de la Región viven, por término medio, cerca de 10 a os menos que los residentes en los países más ricos. Si otros países americanos tuvieran la misma incidencia de tuberculosis que la subregión de Norteamérica (Bermuda, Canadá y Estados Unidos), habría un 76\% menos de casos de esta enfermedad en la Región. En América, cerca de 35\% de las muertes de ni os menores de 1 a o se concentran en $20 \%$ de los nacidos vivos del grupo con menores ingresos. Por otro lado, las muertes maternas asociadas a $20 \%$ de los nacidos vivos del grupo con mayores ingresos representan menos de $2 \%$ de la mortalidad materna. Los análisis de las desigualdades de salud basadas en el uso de diversos métodos destacan la existencia de importantes disparidades entre las subregiones y paí ses americanos que no son fácilmente detectables cuando solo se usan los métodos más tradicionales para el análisis de la mortalidad y morbilidad. También hay necesidad de incorporar los conceptos de distribución y las dimensiones socioeconómicas de la salud al interpretar una determinada situación. El uso de este enfoque les permitirá a las instancias decisorias identificar las áreas y las poblaciones que se encuentran en condiciones más desfavorables. En la actualidad ya existe un volumen considerable de datos agregados, tanto regionales como nacionales, procedentes de los sistemas de información convencionales y referidos especialmente a la mortalidad, la morbilidad y otros factores relacionados con la salud, que se pueden utilizar de forma regular para analizar las desigualdades de salud. Estos tipos de análisis pueden considerarse un primer paso hacia la identificación de las inequidades en salud. 